\title{
O Regulamento SanitáRio InTERnaCional (2005) e a Vigilância em Saúde
}

THE INTERNATIONAL HEALTH REGULATION (2005) AND HEALTH WATCH

Daniel Lins Menucci ${ }^{(\star)}$

\section{RESUMO}

Aborda-se no presente artigo a participação do Brasil e do Mercado Comum do Sul (MERCOSUL) no processo de revisão do Regulamento Sanitário Internacional da Organização Mundial da Saúde (OMS), que teve início em 1995 e foi finalizado em maio de 2005. Numa visão retrospectiva - a partir do exame documental e de relatos da experiência do autor, enquanto testemunha ocular desse processo - são analisadas as principais mudanças introduzidas neste instrumento de direito internacional, bem como as medidas necessárias para a sua implementação em cada país e, especificamente, no Brasil. As conclusões apontam para a necessidade de uma ampla articulação entre os diversos segmentos do setor de saúde e demais setores envolvidos no tráfego e comércio entre países, além da cooperação internacional e do apoio da própria OMS, objetivando evitar a propagação internacional de doenças e seus agentes patógenos.

Palavras-chave

Direito Internacional; Doenças Transmissiveis; Organização Mundial da Saúde (OMS); Vigilância Epidemiológica; Vigilância Sanitária.

(*) Sanitarista, Professor Adjunto da Universidade Federal de Pernambuco, Assessor do Ministério da Saúde/ANVISA, Doutor, Mestre e Especialista na área de saúde mental, saúde do trabalho e saúde coletiva/vigilância sanitária de portos, aeroportos e fronteiras. Integrante da delegação brasileira e umdos pontos focais do Brasil nos fóruns do Mercosul e da Organização Mundial da Saúde para a revisão do Regulamento Sanitário Internacional, desde o ano de 2000 até a $58^{\text {a }}$ Assembléia Mundial da Saúde, em maio de 2005. E-mail:daniel.menucci@saude.gov.br. Recebido em 9.5.06. Aprovado em 30.5.06. 


\section{ABSTRACT}

This article approaches the participation of Brazil and the Common Market of the South (MERCOSUL) in the process of revision of the International Health Regulation of the World Health Organization (WHO) that had beginning in 1995 and was finished in May of 2005. Through a retrospective, from the documentary examination and from the experiences of the author, an eyewitness of this process, the main changes introduced in this instrument are analyzed, as well as the necessary measures for its implementation in each country and, specifically, in Brazil. The conclusions point to the necessity of a large articulation between the different segments of the health sector and others areas involved with the traffic and trade between countries, beyond the international cooperation and of the support of the OMS itself, with the objective of preventing worldwide propagation of diseases and its patogen agents.

\section{Key words}

Epidemiologic Watch; International Law; Sanitary Watch; Transmissible Diseases; World Health Organization (WHO).

\section{INTRODUÇÃO}

Podemos atribuir a um agente patogênico, como os vírus, uma origem geográfica determinada, $e$ até nomear doenças a partir do lugar onde surgem, mas não podemos lhe atribuir uma residência fixa, principalmente neste mundo globalizado!

Este trabalho nasceu a partir do convite da profa. Sueli G. Dallari, em nome do Centro de Estudos e Pesquisa de Direito Sanitário (CEPEDISA) e do Núcleo de Pesquisa em Direito Sanitário (Nap-Disa), da Universidade de São Paulo. O convite pautou-se na intenção de redigir um artigo sobre o "novo" Regulamento Sanitário Internacional (2005), haja vista nosso interesse pelo tema e por termos participado, desde 1998, do processo de revisão deste instrumento de direito internacional.

Pretendemos aqui explorar os antecedentes históricos e as razões da existência e da necessidade de revisão do Regulamento Sanitário Internacional (RSI), enquanto marco normativo internacional da Organização Mundial da Saúde (OMS), que visa prevenir e controlar a propagação internacional de doenças, e suas implicações para a vigilância em saúde, bem como descrever o processo de revisão inclusive quanto à participação do MERCOSUL neste processo. 
Trata-se, portanto, de uma análise de alguém que participou como testemunha ocular deste processo desde 1998, como parte da equipe e da coordenação nacional da vigilância sanitária em portos, aeroportos e fronteiras do Ministério da Saúde/Agência Nacional de Vigilância Sanitária à época, e como um dos pontos focais para este tema, designado pelo governo brasileiro junto aos fóruns do MERCOSUL e da OMS.

O Regulamento Sanitário Internacional visa à adoção de medidas harmônicas entre os Estados-membros da OMS com vistas a impedir a propagação internacional de doenças e seus agentes causadores, evitando-se, ao mesmo tempo, interferir desnecessariamente no tráfego e no comércio mundial.

Essa é uma missão difícil em um mundo globalizado, no qual se estima que a marinha mercante de carga geral, responsável por cerca de $80 \%$ do comércio internacional, emprega a bordo de seus navios cerca de 1,2 miIhões de trabalhadores. No ano de 2000 , cerca de 10 milhões de pessoas viajaram em navios de cruzeiros e se espera que este número duplique até 0 ano de 2010. Em janeiro de 2005, a frota mundial da marinha mercante era constituída de 46.222 embarcações, sendo que $39 \%$ de navios era do tipo carga geral, $25 \%$ de navios tanques/petroleiros, $13 \%$ de graneleiros, $12 \%$ de passageiros e $7 \%$ de containeiros. No Brasil, como reflexo da abertura da navegação de cabotagem, na década de 80 , para os navios de cruzeiro de bandeira estrangeira, cerca de 160 mil pessoas fizeram cruzeiro na costa brasileira no verão passado, esperando-se que na temporada de 2005/2006 este número chegue a 230 mil passageiros ${ }^{(1)}$.

Cada vez mais o transporte marítimo internacional vem desempenhando um papel importante na degradação ambiental, seja pelos resíduos despejados no mar, seja pela redução ou eliminação das barreiras naturais de proteção dos ecossistemas. Essas ações aumentam a homogeneização da flora e da fauna em todo o mundo através do transporte de grande quantidade de água de lastro(2) contida em seus tanques $^{(3)}$, bem como globalizam os

(1) Conforme site da Organização Marítima Internacional (www.imo.org) e notícias divulgadas na imprensa brasileira (Revista "Boa Viagem", novembro 2005).

(2) Para lidar com os problemas causados pela transferência de organismos aquáticos nocivos, exóticos ou patogênicos, a Organização Marítima Internacional - OMI, adotou, em 1997, a Resolução A.868(20), estabelecendo diretrizes para o controle e gerenciamento da água de lastro dos navios. São orientações quanto à escolha do local para captar e descarregar lastro, com a recomendação explícita de que seja efetuada a troca em águas profundas, em mar aberto e afastado da costa, por métodos reconhecidos por aquela organização. Em fevereiro de 2004 a OMl complementa estas medidas com a adoção da Convenção Internacional para Controle e Gerenciamento da Água de Lastro e Sedimentos de Navios. Nesta Convenção está prevista medidas de controle para locais de lastramento e deslastramento, previsão para adoção gradativa de tratamento a bordo, de instalações nos portos, para recepção e destinação ambientalmente segura de água de lastro e sedimentos nela contidos, bem como a troca em alto mar. Quanto à segurança sanitária, há indicadores biológicos para o controle da eficiência dos métodos adotados.

(3) SILVA, Julieta S.V. da SOUZA, Cristina C.L. de Água de lastro e bioinvasão, Rio de Janeiro: Interciência, 2004. 
riscos para a saúde pública, por causa dos resíduos gerados a bordo e por favorecerem um ambiente propício à transmissão internacional de doenças, de pessoa a pessoa ou através de vetores e reservatórios como mosquitos e ratos, por exemplo. Neste sentido, a OMS realizou um estudo no qual identificou, entre 1970 e 2000, mais de 100 surtos de doenças infecciosas relacionadas às embarcações ${ }^{(4)}$.

No que concerne ao transporte aéreo registrou-se em 2004 um fluxo anual de 1,8 bilhões de passageiros, número que deverá aumentar $6 \%$ ao ano até 2008. As aeronaves estão cada vez mais velozes e mais amplas, com a perspectiva de em 2006, transportar, por viagem, até 800 passageiros a bordo. É fato que, num espaço de tempo inferior a 10 horas, é possível fazer a travessia entre a Europa e a América. Estima-se, também, que no Brasil já circulam mais de 10 milhões de passageiros por ano em viagens aéreas internacionais.

Pode-se constatar que o processo de globalização tem acelerado a disseminação de doenças entre os países, demonstrando que hoje a ocorrência de casos localizados de uma determinada doença pode ter um impacto global imediato. A informação que circula livremente sobre o que ocorre com a saúde pública em outros países também pode repercutir localmente, fazendo com que pessoas cancelem ou adiem suas viagens, contratos comerciais sejam afetados e medidas de controle sanitário sejam adotadas.

Por outro lado, o ressurgimento de doenças já esquecidas ou controladas (doenças reemergentes), como a epidemia de Cólera no Peru em 1991 que se espalhou pela América do Sul e a epidemia da Peste que acometeu o oeste da Índia, em 1994 (após terremotos e inundações) assustou o mundo, mas, foi rapidamente controlado com medidas anti-roedores e antibióticos. Também o aparecimento de novas doenças (doenças emergentes) como o Ebola no Congo (antigo Zaire), em 1995, a SARS na Ásia, em 2003 e, recentemente, a Influenza Aviária causada pelo vírus H5N1 são inevitáveis e representam um risco para a saúde pública mundial. Há necessidade do fortalecimento de capacidades nacionais para detecção precoce destes eventos e medidas rápidas e efetivas para o seu controle sanitário, ou, até mesmo, uma resposta coordenada internacionalmente.

Acrescente-se a este panorama o bioterrorismo, agentes químicos e fontes rádio-nucleares e suas possíveis repercussões para a saúde pública internacional. Os eventos acontecidos nos últimos anos, relacionados ao uso do antraz nos Estados Unidos, ao acidente em Chernobyl ou ao gás Sarin num metrô de Tókio são ilustrações claras desse perigo. Estes foram eventos locais com alta repercussão internacional, mas que poderiam ter

(4) WHO - World Health Organization; Sanitation on Ships - Compendium of outrbreaks of foodboorne and waterborne disease and Legionnaires' disease associated with chips 1970-2000. Genebra, Suiça, 2001. 
provocado medidas de controle excessivas e gerado um impacto significativo no tráfego e no comércio internacionais.

É neste contexto que a OMS decide realizar um amplo processo de revisão do Regulamento Sanitário Internacional, sendo o objetivo deste artigo, a partir de agora, fazer uma análise de todo o trabalho realizado.

\section{ORIGENS DO REGULAMENTO SANITÁRIO INTERNACIONAL}

A propagação de epidemias tem uma estreita relação com as viagens internacionais, sendo já conhecida e referida esta relação desde 431 a. C., quando Tucídides relata a propagação da peste na Grécia, vinda da Etiópia, depois Egito e Líbia, através do porto de Pireo em Atenas ${ }^{(5)}$. Esta foi a primeira pandemia de peste que se tem notícia, e alastrou-se por todas as civilizações do mediterrâneo.

Uma segunda pandemia, conhecida como a "peste negra", avançou pelo mundo em 1330 a partir do deserto de Gobi, na Mongólia, afetando grande parte da Ásia, chegou a Alexandria-Egito no Mediterrâneo, e, finalmente, alcançou a Europa em 1347. Tal pandemia foi trazida por um barco italiano vindo da Crimea pelo porto de Messina, Sicília-Itália, chegando em meados de 1348 a Paris e em Londres no final daquele ano. Ela se encerrou no ano de 1665. Esta pandemia correu todo o mundo e teria atingido até $75 \%$ da população da Europa(6), ou mesmo matado metade da população da cidade de Florença-Itáliaa ${ }^{(7)}$.

$O$ entendimento que se tinha sobre a peste naquela época indicava que era transmitida de pessoa a pessoa por algum veneno, pelo hálito ou mesmo pelo olhar. Acreditava-se também na existência de "miasmas" (ar ruim), responsável pela transmissão respiratória de ar envenenado ou atribuído simplesmente a uma maldição divina. Este conhecimento precário levou à adoção de medidas de isolamento e "quarentena"(8), ou mesmo de perseguição aos estrangeiros como os árabes, os peregrinos religiosos e os judeus Fez-se, então, necessária a adoção de medidas sanitárias internacionalmente aceitas que impedissem ou inibissem esta propagação.

(5) NAVARRO Y, GARCIA, Ramon; Historia de la sanidad marítima en España, Madrid: Instituto de Salud Carlos III - Ministerio de Sanidad y Consumo, (1995-1996)

(6) Id. ibid.

(7) FARREL, Jeannette. A assustadora história das pestes \& epidemias. São Paulo: Ediouro, 2003

(8) "Quarentena" refere-se ao termo italiano para designar o periodo de quarenta dias, que durava o isolamento de pessoas doentes ou suspeitas de terem adquirido uma doença contagiosa. 
A cidade de Veneza na Itália despontou como a pioneira na adoção de normas para o controle sanitário das embarcações e seus viajantes, quando, ainda em 1377, proibiu e colocou de quarentena as embarcações provenientes de zonas infectadas pela peste ${ }^{(9)}$. Em 1403 foi construído, naquela cidade, na ilha de Santa Maria de Nazaré, o primeiro lazareto ${ }^{(10)}$ da Europa. Essas medidas foram amplamente difundidas pelo mundo com o intuito de controlar a disseminação de doenças contagiosas que vinham de outros paises $^{(11)}$.

A terceira pandemia de peste, iniciada no interior da China, atingiu o porto de Hong Kong, em 1894, e Bombaim, em 1896, onde matou dez miIhões de pessoas nos 12 anos seguintes. Com a expansão do comércio marítimo ela se disseminou pelos diversos continentes, mais rapidamente através dos navios a vapor, até alcançar a América. Por outro lado o avanço da microbiologia possibilitou identificar o seu agente (bacilo Yersinia pestis $^{(12)}$ ) e seu vetor (pulgas dos ratos infectadas), assim o controle sanitário deslocou-se do homem para os vetores e reservatórios (roedores) e para os ambientes das cidades portuárias. Também os porões das embarcações passaram a ser alvos das medidas sanitárias ${ }^{(13)}$.

Nessa mesma época a varíola espalhou-se pelo mundo trazida do Império Otomano (Turquia) para a Europa, em 1716, já sendo bastante conhecida da Ásia. Tal epidemia foi trazida pelos conquistadores europeus até a América no século XIX e junto com ela veio o hábito da "inoculação"(14), método precursor das vacinas atuais. Com a descoberta da vacina, extraída por Edward Jenner do pus de doentes da "varíola bovina", iniciou-se a fase das medidas profiláticas relativas à imunização. No início, a "varíola bovina" necessária à imunização era transportada para outras regiões do mundo no corpo das pessoas inoculadas. Essa nova medida de proteção foi adotada rapidamente e exigida na Bavária (1807), Dinamarca (1810), Noruega (1811), Rússia (1812) e Suécia (1816), como forma de impedir a propagação da doença.

No Brasil, com a chegada da família imperial e a abertura dos portos às nações amigas pela Carta Régia de 1808, foi então instituído o cargo de

(9) WHO - World Health Organization; Sanitation on Ships - Compendium of outrbreaks of foodboorne and waterborne disease and Legionnaires' disease associated with chips 1970-2000; Genebra, Suíça, 2001.

(10) "Lazareto", designação dada aos locais para isolamento de pessoas doentes ou suspeitas de contraírem doenças contagiosas, derivado do termo italiano "lazaretto", utilizado para designar os estabelecimentos construídos para isolar os leprosos ou "doentes de São Lázaro".

(11) NAVARRO Y GARCIA, Ramon; op. cit.

(12) O nome "yersinia pestis" é em homenagem a Alexander Yersin, que foi aluno de Pasteur, descobridor do germe causador da peste, em 1898, durante a terceira epidemia em Hong Kong.

(13) FARREL, Jeannette. op. cit.

(14) "Inoculação" era uma prática de introdução de secreção de pústulas de pessoas infectadas pela varíola, através de uma agulha, no corpo de outra pessoa sã, visando protegê-la da doença. 
Provedor Mor da Saúde da Corte, em 1809, que tinha, dentre outras atribuições, a competência de cuidar:

".. da conservação da saúde pública; devendo haver todo o zelo, cuidado e vigilância, em que ela não perigue por contágio, fiscalizandose o estado de saúde das equipagens das embarcações, que vêm de diversos Portos, e obrigando-se a dar fundeio em mais distâncias as que saírem de áreas suspeitas de peste, ou moléstias contagiosas, $e$ a demorar-se por algum tempo os que nelas se transportarem; e em se afastarem do uso, e mercados comuns, os comestiveis, os gêneros corrompidos, ou iscados de princípios de podridão".(15)

Essas medidas de controle sanitário adotadas pelas colônias na América do Sul do século XIX repetiam as medidas adotadas pelos colonizadores na Europa, em cada colônia, como fica claro no Alvará de 22 de janeiro de 1810 que Dá Regimento ao Provedor Mor da Saúde:

"... e convindo que para a prosperidade e segurança deste estabelecimento praticado na maior parte das naçôes cultas e civilizadas da Europa, e no porto de Lisboa, que se determine a jurisdição do Provedor Mor, e de mais pessoas empregadas nos negócios desta Repartição, quaes são os objectos da sua incumbencia, e as maneiras com que se devem pôr em pratica as providencias necessárias para conseguir-se o fim útil de conservar-se ilesa de contagio, moléstias epidêmicas e peste, a saúde publica: (...)

1. ... para que se não communiquem enfermidades contagiosas das suas embarcações, equipagens e mercadorias, deverá construir-se um Lazareto, onde façam quarentena, quando houver suspeita, ou certeza de infecção (...)

2. Deverão observar-se a respeito destas embarcações nacionaes ou estrangeiras, suas equipagens e mercadorias, as regras estabelecidas para semelhantes casos, e praticadas reciprocamente pelas $\mathrm{Na}$ çôes a que pertencem, quando não houver decisão própria no regimento do provimento da saúde do porto de Belém de 7 de Fevereiro de 1695, que mando se observe, e as mais ordens determinadas para o porto de Lisboa em tudo que for aplicavel, assim acerca da jurisdição econômica, como da coativa ..."(16)

O texto acima, além de demonstrar a preocupação com o princípio internacional da "reciprocidade", é um instrumento histórico legal e um marco na vigência das ações da vigilância sanitária do Brasil. Seu teor estabeleceu as atribuições do poder de polícia dos "guardas-mores da saúde" existentes nos principais portos do Brasil que foram comandados pelo Provedor

(15) Decreto do Príncipe Regente de 28 de julho de 1809.

(16) Alvará de 22 de janeiro de 1910, que dá Regimento ao Provedor Mor da Saúde. 
Mor, bem como determinou as rotinas de inspeção das embarcações, viajantes, bagagens e cargas que trafegam pelo porto. O texto estabeleceu também certas prerrogativas dos "guardas da saúde" como, por exemplo, o poder de definir o período da "quarentena" em função da verificação iminente da ameaça de contágio, preconizando que:

"... as moléstias que trouxer, mortandade que tenha havido, e mais circunstâncias que occorrerem; porém nunca terão de quarentena menos de oito dias ..."(17)

A cólera foi outra doença que contribuiu bastante para o surgimento de medidas sanitárias de cunho internacional. Ela apareceu inicialmente nas rotas comerciais de países vizinhos à Índia (onde esteve "escondida" por miIhares de anos) tendo sido registrada a sua primeira pandemia entre $1817 \mathrm{e}$ 1823, ficando restrita à Ásia e à África, além da Índia e seus países vizinhos ${ }^{(18)}$.

Foi na segunda pandemia, entre 1830 e 1847, que a cólera chegou à Europa e às Américas. Esse fato conduziu os países a um enorme esforço diplomático de cooperação multilateral internacional no campo da saúde pública que culminou com a Primeira Conferência Sanitária Internacional, ocorrida no ano de 1851 em Paris. Seguiram-se a esta primeira iniciativa mais dez conferências e oito convenções foram negociadas entre os países com o intuito de encontrar, até o final do século XIX, soluções para o controle das doenças transmissíveis.

Como exemplo temos a Conferência Sanitária Internacional de Veneza em 1892, que estabeleceu medidas restritas ao controle da cólera, e a Conferência Sanitária Internacional de 1897, que adotou medidas relativas à peste. Em 1903, essas convenções foram substituídas por outra (que contou com a participação de países não europeus, como o Brasil, os Estados Unidos, o Egito e a Pérsia) que, além de estipular medidas para o controle da peste e da cólera, também procurou definir métodos de controle para a febre amarela. Ênfase foi dada ao controles dos roedores, agentes transmissores da peste e dos mosquitos, causadores da febre amarela.

Posteriormente, todas as convenções foram renegociadas: o Acordo de Roma, assinado pelos países europeus signatários da Convenção de 1903 (com o Brasil e os Estados Unidos, tendo depois recebida a adesão da Argentina, Bolívia, Chile, Canadá, México, Peru e Uruguai ); e ainda em 1903, se deu a criação da "Repartição Internacional para a Saúde Pública" (Office International d'Hygiene Publique - OIHP) com secretariado permanente em Paris ${ }^{(19)}$.

(17) Id. ibid.

(18) FARREL, Jeannette. op. cit.

(19) WHO - World Health Organization - Global crisis - global solutions: Managing public heath emergencies of international concern through the revised International Health Regulations. Genebra, 2002. 
Soares ${ }^{20)}$, citando o prof. Cino Vitta (no seu curso de Direito Sanitário Internacional, da Academia de Direito Internacional de Haia, em 1933) salienta que, mesmo com o fato de muitas dessas Convenções nunca terem entrado em vigor, elas estabeleceram determinados princípios que foram consagrados pelas legislações dos Estados em suas normas internas, tais como: a obrigação de notificar oficialmente a outros países a existência de doença epidêmica em seu território, obrigatoriedade dos navios estarem de posse de declarações/patentes de saúde, dever de indicar agentes sanitários oficiais em portos estratégicos para o controle sanitário, bem como o estabelecimento de limites de tempo permitido para quarentenas. Também havia, com isso, uma tentativa de descrever e estabelecer condutas específicas para evitar a propagação de cada doença quarentenária indicada.

Em paralelo e em harmonia com o movimento europeu, na América do Sul, em 25 de novembro de 1887, foi assinada a "Convenção Sanitária entre o Império do Brazil, a República Argentina e a República Oriental do Uruguay", dando início a primeira iniciativa de acordo internacional para a saúde pública entre países do cone Sul. Essa Convenção trinacional declarou como "moléstias pestilenciais exóticas" a febre amarela, o cholera-morbus e a peste oriental, para as quais se previu uma série de medidas a serem adotadas nas embarcações e nos portos, inclusive o compromisso de instalação de "serviços sanitários" específicos em cada país. São exemplos destas medidas: 1) não conceder a livre prática sem inspeção prévia a bordo; 2) exigência de carta sanitária do porto de procedência, visada pelos cônsules do país de destino e de "bilhete sanitário" (descrevendo as medidas adotadas nos portos dos países signatários da Convenção); e 3) a adoção de quarentena e medidas de desinfecção, por um "corpo de inspetores sanitários de navio" (médicos). As medidas ficavam a cargo de cada país, sem intermediação de qualquer organismo internacional multilateral; mas, que repetiam as recomendações advindas das Conferências Sanitárias européias realizadas naquela época.

Em 1902, foi realizada em Washington a Primeira Conferência Sanitária das Américas, com a presença de 11 países, estabelecendo a Repartição Sanitária Pan-Americana, precursora da Organização Pan-Americana de Saúde (OPAS) (que teve sua constituição adotada em 1947). Em 14 de novembro de 1924, durante a VII Conferência Sanitária Pan-Americana, em Havana, Cuba, 21 países americanos assinaram o Código Sanitário PanAmericano, que visava à prevenção da propagação internacional de infecções transmissiveis; à cooperação e o intercâmbio de informações entre os países, para melhorar a saúde pública e combater doenças, além da padronização de medidas adotadas nos pontos de entrada. Esse código só foi

(20) SOARES, Guido F. S. O direito internacional sanitário e seus temas: apresentação de sua incômoda vizinhança, Revista de Direito Sanitário, São Paulo, V. 1, n. 1, p. 49-88, 2000. 
modificado em 1952, como conseqüência do primeiro Regulamento Sanitário Internacional, adotado em 1951 pela Organização Mundial da Saúde (fundada em 7 de abril de 1948), que uniu os esforços europeus e panamericanos em um único instrumento regulatório, numa mesma organização, já que a OPAS passou a ser também um escritório regional da OMS ${ }^{(21)}$.

Solidifica-se assim a prática da "diplomacia parlamentar", própria dos organismos multilaterais e que foi exercida à semelhança dos parlamentos nacionais, dentro de organizações intergovernamentais. Para Soares este movimento em direção ao reforço e ampliação do papel dos organismos multilaterais é uma conseqüência da facilidade de comunicação e transporte no século XX e efeito do processo da globalização que enfraqueceu os elementos inerentes à soberania nacional. Dito processo:

“... tem tornado as fronteiras interestatais elementos superados, num ambiente onde o mercado é mundial e único e onde, de igual forma, as forças de destruição transitam sobranceiras por sobre os poderes regulatórios dos Estados ou os espaços ou elementos dignos da proteção são trasnfronteiriços. Tais fenômenos, insistimos, são causados seja devido à maior freqüência do movimento internacional de pessoas e bens, seja porque há fenômenos que desconhecem fronteiras físicas entre Estados, como os hábitats protegidos internacionalmente, inclusive as cidades integrantes do Patrimônio Cultural da Humanidade $e$ as obras de arte, seja porque as poluições atmosféricas, marítimas, fluviais e de lençóis freáticos não respeitam limites políticos entre os Estados, tornando indissociável a necessidade de uma regulamentação internacional de seus efeitos, às necessidades de cooperação internacional. "(22)

Seriam então, segundo aquele autor, a liberdade do comércio internacional junto com a proteção internacional ao meio ambiente, incômodos vizinhos do direito internacional sanitário, do qual o Regulamento Sanitário Internacional faz parte.

Assim como assistimos a evolução dos instrumentos normativos internacionais, que culminou com a adoção de instrumentos multilaterais, também podemos verificar que o controle das doenças ditas "infecciosas" mudou com a experiência adquirida após as epidemias, com seus efeitos no tráfego e comércio internacional e com o desenvolvimento do conhecimento científico sobre as doenças e seus agentes patogênicos. Para Waldman ${ }^{(23)}$

(21) OPAS - Organização Pan-Americana de Saúde. Regulamento Sanitário Internacional: Perspectivas da Região das Américas. Conselho Diretor, CD45/12, 2004 e informações no site Disponível em: www.paho.org .

(22) SOARES, Guido F. S. op. cit. p. 49-88.

(23) WALDMAN, Eliseu A. O controle das doenças infecciosas emergentes e a segurança sanitária, Revista de Direito Sanitário, São Paulo, v. 1, n.1, p. 88-106, 2000. 
os instrumentos de controle de doenças infecciosas, como a quarentena e o isolamento, fortemente utilizados entre a Idade Média e o século XIX, precederam ao desenvolvimento da microbiologia e a uma discussão científica sobre o conceito de controle sanitário. Tratava-se mais de uma estratégia para defender as pessoas sadias. Posteriormente, surgiu o instrumento do "cordão sanitário", uma extensão dos dois primeiros que visava agora à proteção de "áreas limpas", como bairros, cidades ou áreas delimitadas, a partir do isolamento de zonas afetadas por determinada doença contagiosa. Eram instrumentos de caráter restritivo, policial e, até certo ponto, punitivo, que também criavam entraves ao comércio internacional, principalmente ao marítimo que estava em franca expansão no final do século passado (e, juntamente com ele, expandia-se também o risco de epidemias).

A ampliação do conhecimento na microbiologia e o melhor entendimento dos mecanismos de transmissão das doenças contagiosas fizeram surgir a noção de "vigilância", enquanto "inteligência epidemiológica", como instrumento de controle. Tais procedimentos visavam detectar precocemente os primeiros sintomas das doenças mediante a observação dos suspeitos de terem tido contato com o agente infeccioso durante o período de incubação. Somente após essa primeira intervenção é que seriam adotadas medidas restritivas de isolamento dos enfermos. A esse instrumento somaram-se a "monitorização" e a "fiscalização" sanitária já na metade do século XX, completando o arsenal para as ações de controle ${ }^{(24)}$, que, de uma forma ou de outra, aparecem no Regulamento Sanitário Internacional.

O Regulamento Sanitário Internacional de 1951 tinha como propósito o monitoramento e controle de seis doenças infecciosas graves: cólera, peste, febre amarela, varíola, febre recorrente e tifo. Em 1969 o regulamento sofreu sua primeira revisão, e em 1973 novas alterações foram feitas com a inclusão de medidas adicionais para o controle da cólera. Em 1981, foram excluídas as exigências em relação à varíola cuja erradicação havia sido

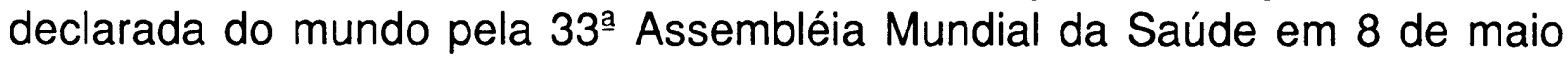
de 1980. A última revisão do Regulamento Sanitário Internacional, objeto deste trabalho, iniciou-se em 1995 e foi finalizada em maio de 2005, devendo entrar em vigor em 15 de junho de 2007.

\section{O REGULAMENTO SANITÁRIO INTERNACIONAL (1969)}

O Regulamento Sanitário Internacional (1969), em sua versão corrigida e aumentada, vigente desde $1^{\circ}$ de janeiro de 1982 , agora restrito apenas ao controle da cólera, da febre amarela e da peste, traz descrito no seu preâmbulo a sua finalidade principal que se refere a:

(24) WALDMAN, Eliseu A. op. cit., p. 88-106. 
".. conseguir a máxima segurança contra a propagação internacional de doenças com o mínimo de barreiras ao tráfego internacional ..."(25)

Estimula ainda a aplicação internacional dos princípios epidemiológicos e seus instrumentos de controle sanitário para:

“... descobrir, reduzir ou eliminar as fontes de propagação de infecções, melhorar as condições de saneamento nos portos e aeroportos e suas imediações, impedir a difusão de vetores e, em termos gerais, fomentar as atividades epidemiológicas nacionais para reduzir em todo o possivel o risco de implantação de infecções procedentes do exterior ..." (26)

As medidas nele previstas são as máximas que um país signatário poderá adotar em relação às três doenças que são seu foco de controle e possuem o intuito de evitar medidas excessivas que tragam reflexos indesejáveis e desnecessários ao tráfego internacional. Essas medidas incluem a vacinação e a emissão de Certificado Internacional de Vacinação para febre amarela, desratização, desinsetização e desinfecção de aeronaves e embarcações, bem como os respectivos certificados sanitários sobre as medidas adotadas, além de medidas permanentes sobre a qualidade da água, dos alimentos e de controle de vetores nos aeroportos e portos (e, excepcionalmente, nos pontos de fronteira terrestres), sujeitos ao Regulamento. Há ainda medidas específicas para os resíduos líquidos e sólidos, quando se tratar de meios de transportes suspeitos para a transmissão de cólera.

O Regulamento em vigor possui limitações, não apenas quanto à notificação oficial de apenas três doenças por iniciativa do país afetado, mas também pela falta de mecanismos de colaboração entre a Organização Mundial de Saúde e os países afetados; pela falta de incentivos para o seu cumprimento por todos os Estados-membros e pela ausência de medidas específicas para prevenção de surtos/eventos específicos.

\section{O PROCESSO DE REVISÃO DO REGULAMENTO SANITARIO INTERNACIONAL}

Considerando as limitações do Regulamento em vigor e o surgimento de novas doenças, também o ressurgimento de outras já conhecidas associadas ao grande risco de sua rápida propagação internacional, tendo em vista o fenômeno da globalização e do conseqüente aumento do comércio e trânsito internacional de pessoas e meios de transporte, a $48^{\mathrm{a}}$ Assembléia

(25) OMS — Organização Mundial da Saúde — Regulamento Sanitário Internacional, 3 ed. Genebra, 1983 (26) Id. ibid. 
Mundial de Saúde realizada em 1995, emitiu a Resolução WHA48.7 determinando o início do processo para revisão do Regulamento Sanitário Internacional.

Esse processo de revisão encerrou-se dez anos após, em maio deste ano, com a adoção do Regulamento Sanitário Internacional (2005) pela 58 Assembléia Mundial da Saúde através da Resolução WHA58.3, que insta os 192 Estados-membros da OMS a adotarem medidas imediatas para a sua ratificação e implementação em cada país, antes mesmo da sua entrada em vigor em 15 de junho de 2007.

\subsection{Primeira fase do processo de revisão (1995-1999): a vigilância por síndromes e o primeiro rascunho informal}

Podemos caracterizar essa primeira fase como aquela relacionada estritamente com as medidas ligadas às doenças transmissíveis. Nesta fase a preocupação maior foi a de abarcar todas as doenças emergentes e reemergentes que não constavam da lista de notificação do Regulamento em vigor. Estávamos sob o impacto do ressurgimento de surtos de peste (Índia, 1984), cólera (América do Sul, com maior disseminação entre 1990 e 1995) e do aparecimento de doenças como o Ebola (África, 1994), que atingiram grande número de pessoas e com alto impacto para o comércio internacional.

Esta fase iniciou-se com a adoção da Resolução WHA48.7, de 12 de maio de 1995, durante 48a Assembléia Mundial de Saúde, que instou os Estados-membros da OMS a participar da revisão do Regulamento Sanitário Internacional vigente e pediu a colaboração para outras agências especializadas e organizações do sistema das Nações Unidas, bem como para organizações não-governamentais e outros grupos interessados no tema.

Entre os dias 11 e 14 de dezembro de 1995, realizou-se em Genebra uma consulta informal a um grupo de peritos de diversas áreas (epidemiologia, imunologia, virologia, bacteriologia e parasitologia, saúde ambiental, estatística em saúde e saúde do viajante) que emitiram algumas recomendações-chave para o processo de revisão, a saber:

1 - Revisar e expandir o papel e a função do RSI, particularmente sobre o limite de notificação de três doenças apenas (cólera, febre amarela e peste), substituindo essa lista por uma notificação imediata de síndromes predefinidas que representem a ocorrência de doenças de importância internacional, com repasse de todas as informações epidemiológicas básicas e úteis para as medidas de controle de doenças;

2 - Desenvolver um manual prático, definindo critérios que indiquem os requisitos para a notificação internacional e facilite o uso do RSI; 
3 - Integrar o RSI a todas as atividades de vigilância e controle epidemiológico, nos níveis global, regional e nacional;

4 - Incluir no RSI uma descrição de intervençōes inapropriadas ou desnecessárias, com indicaçōes claras das razões pelas quais essas açōes não são requeridas.

Em 28 de março de 1996, através da Carta Circular C. L. 5.1996, o Diretor Geral da OMS convida os Países-membros a indicarem um perito nacional para servir como "ponto focal" para a revisão do RSI e noticiou a realização da consulta informal ocorrida em dezembro, pedindo comentários sobre as recomendações emanadas do grupo de peritos estipulando o prazo máximo até 30 de abril de 1996 para o envio destes comentários.

Em 2 de agosto de 1996 a OMS publicou seu primeiro informe sobre os avanços no processo de revisão do RSI no Weekly Epidemiological Record, referendando o resultado da consulta informal do grupo de peritos, salientando, além das recomendações acima citadas, que os princípios básicos do $\mathrm{RSI}$, dentre eles assegurar a máxima segurança contra a disseminação internacional de doenças com o mínimo de interferência no tráfego e comércio mundial, continuam válidos e que a coordenação global é vital para monitoramento, notificação e resposta. Mais ainda, que o controle de doenças infecciosas em nivel internacional é mais efetivo com a melhoria da vigilância e estratégias de intervenção do que com a aplicação de medidas em fronteiras, distantes da fonte de infecção. Finalmente, informou que desde a adoção da Resolução WHA48.7, em 12 de maio de 1995, somente cerca de 50 países designaram peritos para servirem de ponto focal nacional neste processo, em atenção à Carta Circular de março de 1996. Alguns fizeram comentários sobre as recomendaçōes propostas, especialmente quanto à necessidade de restringir e melhor definir a notificação por síndromes.

No mês de dezembro de 1996 foi publicado o segundo informe sobre o processo de revisão. Nele havia informações de que se constituiu um pequeno grupo de trabalho, após a consulta informal de dezembro de 1995, com o objetivo de elaborar um rascunho para circular entre os países. Esse grupo se reuniu entre os meses de setembro e novembro daquele ano, com consultas e informações intercaladas e sugeriu ser necessário um teste prático das medidas propostas em alguns países selecionados, representando as diversas regiōes do planeta, durante seis meses antes da elaboração de uma proposta final para discussão. Informou-se ainda, neste encontro, que todos os países deveriam receber convite para colaborarem com esse teste de campo. Foram nomeados também os membros do Comitê de Vigilância Internacional para as Doenças Transmissíveis da OMS, que também teve participação ativa nesse processo, fixando-se ainda os próximos passos a serem percorridos no seis meses seguintes. Por último foi informado que apenas 44 países (dos 192 Membros da OMS) indicariam peritos para serem pontos focais nacionais, até aquela data (estranhamente um número menor que o informe anterior, no mês de agosto!). 
Em 11 de fevereiro de 1997 o Diretor Geral da OMS emitiu outra Carta Circular C. L. 1.1997, reiterando o pedido de indicação de peritos nacionais para a revisão do RSI. Em julho daquele ano essa informação chegou a então Secretária de Vigilância Sanitária do Ministério da Saúde (SVS/MS), que indicou o Dr. Hélio Pereira Dias (então chefe da assessoria jurídica daquela Secretaria) e o Dr. Lúcio Flávio Castro Nasser (então Coordenador de Portos, Aeroportos e Fronteiras da mesma Secretaria, que ficou apenas até janeiro de 1998 nesta função). Em outubro daquele ano a Assessoria Internacional do Ministério da Saúde repassou a indicação destes nomes para que o Ministério das Relações Exteriores transmitisse a informação à OMS.

Em janeiro de 1998 a OMS colocou em circulação um "rascunho provisório" (provisional draft) com proposta de revisão do texto do RSI, tendo como base as recomendações-chave propostas pelo grupo de peritos da consulta informal realizada em dezembro de 1995. Tratava-se de uma proposta de retirada de referência a doenças específicas para notificação, em troca de uma "vigilância sindrômica". Tal proposta obrigava os Países-membros a notificarem imediatamente qualquer caso, surto ou epidemia relacionados a uma das sindromes sujeitas ao Regulamento, a saber:

1 - Síndrome da Febre Hemorrágica Aguda;

2 - Síndrome Respiratória Aguda;

3 - Síndrome Diarréica Aguda;

4 - Síndrome Ictérica Aguda;

5 - Síndrome Neurológica Aguda; e

6 - Outras Síndromes Notificáveis, referentes a outras doenças graves, não incluídas nas precedentes e que tenham casos agregados que possam ser caracterizados como uma "urgência importante para a saúde pública internacional".

O texto propôs enxugar ao máximo o corpo do Regulamento e deslocou para seus anexos todas as medidas de vigilância e controle a serem adotadas, inclusive a definição das seis síndromes. O texto tentou ainda introduzir no art. 56, a idéia da criação de um "Comitê Arbitral" dentro do âmbito da OMS para solução de controvérsias, como instância final de decisão, que não vingou nas versões posteriores. Também apareceu no seu art. 4 o direito da OMS requerer e receber resposta imediata sobre informações acerca de notificações de problemas de saúde recebidas de "outras fontes de boa reputação", tais como dos Centros Colaboradores, de outras autoridades do mesmo país, organizações internacionais atuando na localidade e de autoridades nacionais de países vizinhos.

Entre os meses de março e abril de 1998, após tomar conhecimento desse documento, a Coordenação de Portos, Aeroportos e Fronteiras da SVS/MS emitiu o "Memo Circular". O documento provisório tratava do RSI e 
suas possíveis modificações e foi encaminhado para exame e sugestões por parte dos Serviços de Vigilância Sanitária de Portos, Aeroportos e Fronteiras, localizados em cada Unidade da Federação. O Dr. Helio P. Dias, ponto focal do Brasil para esse processo na época, coordenou então a primeira reunião de um pequeno grupo de sete técnicos (onde se incluía o autor), para consolidar as sugestões recebidas. Nesta ocasião já havia a preocupação com o uso de informações não oficiais, conforme proposto no documento em discussão, que não fossem validadas pelos Países-membros, bem como com a limitação de critérios para a definição de "urgências importantes para a saúde pública internacional" (urgent international public health importance) exclusivamente para as condições sanitárias e síndromes de que tratava 0 rascunho do $\mathrm{RSI}$ apresentado naquela ocasião.

Em 26 de junho de 1998 a OMS, através de correspondência assinada pelo Dr. L. J. Martinez (Gerente Sênior de Programas da Divisão de Vigilância e Controle de Doenças Emergentes e outras Doenças Transmissíveis) acusou o recebimento das sugestões enviadas pelo Dr. Helio P. Dias (ponto focal brasileiro), referentes ao Ofício SVS/GABIN n. 172/98 e informou que até o final daquele ano estaria circulando uma segunda versão do documento apresentado em janeiro. Registrou-se ainda a modificação no cronograma de trabalho que agora previa a finalização da revisão durante o período de $1999 / 2000$, após a conclusão do estudo piloto de campo, que estava em andamento em 21 países, inclusive no Brasil, coordenado nacionalmente pelo então Centro Nacional de Epidemiologia da Fundação Nacional de Saúde (FUNASA). O estudo piloto sobre a notificação de síndromes, iniciado em outubro de 1997, foi finalizado em março de 1999.

Em abril de 1999, durante a $52^{\mathrm{a}}$ Assembléia Mundial da Saúde, circulou o documento A52/9 - Revisão e Atualização do Regulamento Sanitário Internacional, contendo: informes sobre os Progressos Realizados; local do registro da análise resultante da reunião do Comitê de Vigilância Internacional de Doenças Transmissíveis, realizada em novembro de 1998 e que recomendava manter-se a notificação oficial feita à OMS apenas pelas autoridades nacionais, reafirmando a conveniência do uso de notificação de síndromes. Também fazia referência à necessidade de ampliação dos prazos para a conclusão dos trabalhos, tendo sido fixado o ano de 2002 para apresentação do novo RSI à Assembléia Mundial da Saúde. Surgiu neste documento a primeira manifestação da Organização Mundial do Comércio (OMC), quanto a uma possível interface do seu Acordo sobre a Aplicação de Medidas Sanitárias e Fitossanitárias (Acordo SPS) com o RSI, referindo-se aos princípios comuns de redução dos obstáculos ao comércio internacional, presentes em ambos os instrumentos internacionais. Foi salientado o papel da OMS no apoio à OMC para solucionar possíveis controvérsias que pudessem surgir em decorrência de surtos de doenças, bem como para evitar um conflito na aplicação do RSI e das medidas previstas no Acordo SPS. Nesta ocasião a delegação do Brasil manifestou-se em plenário, apoiando o processo de 
revisão do RSI e lembrando da necessidade de uma perfeita integração entre a aplicação do RSI e do Acordo SPS, e sugerindo a organização de seminários sobre o tema saúde e comércio, oferecendo-se ainda para realizá-los no Brasil.

Dando seguimento a essa discussão sobre a relação entre o RSI e outros instrumentos que tratam da segurança sanitária no comercio internacional, a OMS publicou um artigo no Weekly Epidemiological Record, em 25 de junho de 1999, comparando o papel da OMC, da Comissão Codex Alimentarius da FAO (Organização para a Agricultura e Alimentos) e da OMS, tendo em vista a aplicação dos seus acordos e regulamentos internacionais relacionados a saúde pública. Tratou-se de um artigo que serviu como referência para muitas das discussões que se sucederam durante o processo de revisão do RSI. Nele foram analisadas as bases jurídicas, propósitos, princípios básicos, estrutura organizacional, funções essenciais, direitos e obrigações dos membros, mecanismos de solução de controvérsias e as relações comuns entre as três Organizações, salientando-se o papel crítico das notificações em tempo adequado, para a adoção de medidas de controle sanitário, de modo a evitar danos à saúde pública e entraves ao comércio internacional.

No contexto nacional, naquele exato momento, o Ministério da Saúde discutia a criação de uma "agência" para as atividades de vigilância sanitária no país, sobre o qual ainda não havia uma definição quanto à reorganização das ações desenvolvidas pelo Ministério da Saúde nos portos, aeroportos e fronteiras. Paralelamente, iniciaram-se, ainda no primeiro semestre de 1998, atividades para a inserção do setor de saúde no recém-criado Sistema Integrado de Comércio Exterior - SISCOMEX, que visava ao controle informatizado e integrado das importações e exportações sujeitas à anuência de diversos ministérios, além do controle aduaneiro e cambial. Também parte das ações exercidas pela FUNASA estavam sendo descentralizadas para os Estados e Municípios, tais como o controle de vetores que também era realizado nos pontos de entrada do país. Em suma, pairava no ar um clima de "mudança" e reestruturação das ações de vigilância sanitária e epidemiológica no Brasil.

\subsection{Segunda fase do processo de revisão (2000 - 2003): a introdução do conceito de eventos urgentes de saúde pública de interesse internacional}

Em 10 de janeiro de 2000, após encerramento do estudo piloto sobre a notificação de síndromes e análise dos seus resultados pelo Comitê de Vigilância de Doenças Transmissíveis, o Diretor Geral da OMS aprovou novas diretrizes para a revisão do RSI, sintetizadas num rascunho de documento divulgado em 22 de fevereiro daquele ano, intitulado "Revisão do Regulamento Sanitário Internacional - documento de posiçóes políticas". As seguintes propostas de diretrizes foram feitas então: 
1 - Manter o objetivo do RSI em "garantir a máxima segurança contra a disseminação internacional de doenças com a mínima interferência ao tráfego mundial".

2 - O novo RSI não terá uma lista de doenças notificáveis, nem dependerá somente do uso de síndromes para notificação. Em vez disso irá requerer a notificação de "todos os eventos de urgência internacional de importância para a saúde pública" (urgent international public health importance).

3 - Cada país necessitará de um ponto focal para o processo do RSI;

4 - Os Estados-membros terão a opção de fazerem notificações temporárias à OMS em caráter confidencial.

5 - Outras informações não oficiais serão utilizadas pela OMS para ajudar no controle de eventos de saúde pública de urgência internacional (urgent international public health events), com a obrigação dos Estados-membros responderem aos pedidos de informação feitos pela OMS, com propósitos de verificação da veracidade da informação;

6 - Haverá uma obrigação da OMS em assistir rapidamente aos Estados-membros na avaliação e controle de surtos.

7 - Haverá um processo transparente na OMS para declarar um evento como urgência de saúde pública internacional.

8 - O RSI conterá uma lista de todas as possíveis medidas essenciais que podem ser utilizadas numa determinação da OMS, que serão recomendadas de acordo com o impacto potencial do evento.

9 - O RSI terá um processo de apelação, para os Estados-membros poderem questionar as diretrizes adotadas pela OMS.

10 - A existência de outras Organizações envolvidas nos temas de saúde e comércio deve ser explicitada no RSI, com respectivas áreas de responsabilidade delineadas e possíveis sinergias exploradas.

Em 30 de maio de 2000, um relatório do processo de revisão explicitou o conceito básico para a revisão do RSI: os eventos urgentes de importância internacional relacionados à saúde pública devem ser notificados à OMS. Para tanto o RSI contaria com um algoritmo para tomada de decisão sobre quando um evento deve ser visto como urgente e internacional. Nessa ocasião circulou entre os países a proposta deste algoritmo, já revisado a partir de sua utilização no estudo piloto.

Em 31 de maio de 2000 a OMS submeteu à apreciação do Comitê de Medidas Sanitárias e Fitossanitárias da OMC um segundo documento informativo, G/SPS/GEN/179, intitulado "Crises Globais - Soluções Globais: gerenciando eventos de urgência em saúde pública internacional com o Regulamento Sanitário Internacional Revisado", com vistas a discuti-lo em 
uma reunião informal entre representantes da OMS e daquele Comitê, entre os dias 22 e 23 de junho do mesmo ano. Nele foram apresentados todos os dez itens das diretrizes aprovadas em janeiro pelo Diretor Geral da OMS e divulgadas no final de fevereiro (e também em maio).

Durante o ano de 1999 e no primeiro semestre do ano de 2000, o documento com o rascunho de janeiro de 1998 foi analisado e discutido internamente no Brasil, entre o setor de saúde (vigilância sanitária e vigilância epidemiológica) juntamente como os informes recebidos e publicados pela OMS. No início do segundo semestre, nos dias 14 e 15 de setembro de 2000, organizou-se a primeira reunião (paralela à XII Reunião Ordinária do SGT-11-Saúde - MERCOSUL) para discutir o processo de revisão juntamente com os Estados, parte do MERCOSUL e Chile, ainda com participação de representantes da OPAS/OMS. Nessa ocasião os temas discutidos foram: a questão do equilíbrio entre os aspectos sanitários e comerciais; o uso do algoritmo para a notificação; notificações em caráter temporário e transitório; capacidade mínima requerida para os pontos de entrada; o uso de fontes não oficiais de informação e verificação; transparência no processo de decisão; lista das medidas sanitárias previstas; mecanismos de apelação; e processos de desinsetização nas embarcações e aeronaves.

Ficou evidente que o RSI em vigor estaria incentivando a construção de um controle sanitário nos pontos de entrada, em detrimento da integração com sistemas de vigilância epidemiológica. A proposta de utilização do algoritmo apresentado pelo representante da OPAS, para notificação de eventos urgentes relacionados à saúde pública internacional, mostrou-se como um desafio aos países, por terem que repensar seus sistemas de vigilância e controle. Houve um consenso, naquele momento, quanto à necessidade de se incentivar a notificação adequada e à necessidade do apoio necessário por parte da OMS, para a construção de um sistema de informação epidemiológica global que funcionasse para os propósitos do RSI.

Essas reuniões se repetiram semestralmente, dentro do MERCOSUL, sendo, posteriormente criado um Grupo de Trabalho Assessor, junto à Reunião de Ministros de Saúde do MERCOSUL e Estados Associados - RMSM-EA, para acompanhar o processo de revisão do RSI. Em cada uma dessas reuniões tínhamos a participação de representantes da OPAS/OMS, que traziam os últimos informes e davam apoio às discussões que ocorriam neste fórum.

Logo após esta reunião, a OMS através de uma correspondência assinada pelo Dr. David L. Heymann (Diretor Executivo para Doenças Transmissíveis), e datada de 31 de outubro de 2000, convidou o Ministério da Saúde do Brasil a participar como parceiro próximo (close partner) da revisão do $\mathrm{RSI}$, tendo em vista a experiência do país no desenvolvimento de instrumentos de vigilância e resposta para doenças transmissíveis, sua vulnerabilidade para as ameaças advindas das doenças e sua posição de liderança no 
comércio internacional. As áreas de trabalho identificadas para esta colaboração incluíram a vigilância e a notificação de doenças, mecanismos de resposta a surtos, inspeção e emissão de certificados para os meios de transporte e viajantes nos pontos de entrada internacional, inspeção e padrões para alimentos, representação na OMC e serviços jurídicos.

Em maio de 2001, a 54a Assembléia Mundial da Saúde adotou a Resolução WHA54.14 - Segurança Sanitária Mundial: alerta e resposta frente a epidemias -, na qual expressou seu apoio ao trabalho de revisão do RSI, instando os Estados-membros a, junto com a OMS e outros técnicos associados, participarem ativamente na verificação e validação de dados e informações de vigilância relativa às emergências sanitárias de interesse internacional. Também solicitou o empenho dos Estados-membros e o apoio da OMS para a elaboração de planos nacionais e regionais de preparação e resposta, no sentido de desenvolver e capacitar pessoal, atualizando regularmente as informações sobre os recursos de vigilância epidemiológica disponiveis, um ponto focal para o RSI. Este documento deixou mais claro ainda a tendência a ser seguida daqui para frente: o fortalecimento de uma "inteligência epidemiológica" e implementação de planos de alerta e resposta, evitando-se falar da adoção de "barreiras sanitárias" e medidas de controle em pontos de entrada.

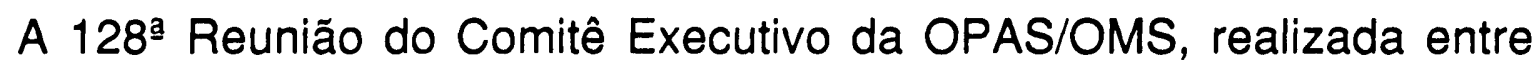
22 e 29 de junho de 2001, adotou a Resolução CE 128.R1 - Regulamento Sanitário Internacional, que propôs ao Conselho Diretor da OPAS adotar uma Resolução apoiando o processo de revisão do RSI e, especialmente, solicitou aos Estados-membros que revissem os critérios para definir um "evento de saúde pública de importância internacional em potencial". Também foi apresentado nesta mesma reunião, através do documento CE 128/ 14 , um informe detalhado dos antecedentes e progressos alcançados, bem como as mudanças-chave propostas, referentes ao documento para uma política de revisão do RSI, apresentado anteriormente (precisamente em janeiro de 2000, pelo Diretor Geral da OMS).

Entre os dias 19 e 21 de setembro de 2001, a ANVISA promoveu uma segunda oficina nacional para discutir a revisão do RSI, com a presença de representantes da delegação nacional do MERCOSUL-SGT-11-Saúde, do Cenepi/FUNASA/MS; Geipot/MT, SES/MG e da OPAS. Nesta ocasião, propôs-se um avanço, para além dos aspectos de alerta e resposta às emergências sanitárias, solicitando que o RSI também abrangesse os aspectos relacionados à "promoção em saúde". Nesse sentido, a idéia de abdicar da existência de listas de doenças de notificação obrigatória seria prematura, devendo estas listas ser ampliadas para que abarcassem outras doenças, mesmo não-transmissíveis, com vistas a uma contínua análise da situação de saúde de cada país, sendo o uso das doenças notificadas um bom indicador de saúde e orientador das práticas neste campo. 
Quanto ao monitoramento internacional, sugeriu-se ainda que seria aceitável uma tendência à vigilância por síndromes; mas, desde que esta fosse vinculada à estruturação de sistemas de notificação e informação e que integrasse a vigilância sanitária, epidemiológica e ambiental dentro da concepção de uma "vigilância em saúde". Esta discussão deixou claro que não mais estávamos falando apenas de "doenças transmissíveis", de agravos na saúde pública, mas também de determinantes da saúde internacional. Essa forma de ver o papel do RSI também teve reflexos na concepção do papel dos pontos de entrada e saída internacionais, que não deveriam ser vistos apenas como "barreiras sanitárias", mas também como promotores de saúde, ou seja, teriam que ser "ambientes saudáveis", certificados pela OMS, nos quais o controle sanitário de saída devesse ser reforçado, no sentido de que cada país só deixasse passar ali o que não fosse nocivo (non nocere, como um dos princípios de atuação). Isto nos levou a pensar nos pontos de entrada como "pontos de apoio" aos viajantes, e não como "pontos de contágio". Para lidar com as emergências sanitárias deveria haver planos de contingência previamente estabelecidos.

Em janeiro de 2002, foi realizada uma reunião de peritos, sob os auspícios da OMS e do Instituto Sueco para o Controle de Doenças Infecciosas, na Suécia, com participação do Brasil. O intuito desta reunião foi definir um instrumento de decisão com vistas a identificar eventos urgentes em saúde pública que estariam sujeitos à notificação internacional. Na ocasião, elaborou-se uma lista de critérios, surgindo a primeira versão de um algoritmo do que viria a ser o instrumento de decisão do anexo 02 do "novo" RSI. Esse instrumento foi então apresentado no dias 13 e 14 de março do mesmo ano, numa reunião em Londres, com representantes dos países do G7, quando se revisava a preparação global para o uso intencional de agentes biológicos.

Estávamos sob o impacto de eventos como o fatídico "11 de setembro" (atentado no World Trade Center, em Nova York), o atentado por gás Sarin no metrô de Tóquio e a liberação intencional de antraz produzido em laboratório. Impacto este que se fez sentir também no rumo das negociações para o RSI e nas decisões da OMS. Um exemplo disto foi a adoção da Resolução WHA 55.16, de 18 de maio de 2002, elaborada durante a 55a Assembléia Mundial da Saúde e que se caracterizou por ser uma resposta global em saúde pública para ocorrência natural, liberação acidental ou uso deliberado de agentes biológicos, químicos ou materiais rádio-nucleares que afetem a saúde. Tratou-se de uma Resolução que instava os Estados-membros a tratarem qualquer liberação intencional desses agentes e materiais rádionucleares que causem danos às pessoas, como uma ameaça a saúde pública. Esta Resolução iria, mais tarde, ser utilizada como justificativa para ampliar o propósito e a finalidade do RSI.

Até este momento, as discussões estavam dentro de um patamar mais "técnico" e de "estratégias de intervenção" no campo da saúde, à exceção 
das preocupações, sempre presentes, com o comércio internacional. Isto ficou evidente, quando, em 15 de dezembro de 2002, no informe feito na $111^{\text {a }}$ Reunião do Comitê Executivo da OMS, foi solicitada a extensão do prazo para conclusão dos trabalhos de revisão do RSI, tendo em vista que nesta etapa as discussões técnicas deveriam ser ampliadas para o "nível político", com a proposta de realização de uma série de reuniões coordenadas pelos diretores regionais da OMS. Nesta ocasião, também houve o informe sobre o andamento da revisão do Guia Sanitário de Embarcações e do Guia de Higiene e Saúde na Aviação, processo do qual o Brasil também teve participação ativa, nas reuniões técnicas informais e consultas feitas por teleconferência.

Em 24 de janeiro de 2004, o Comitê Executivo da OMS adotou a Recomendação EB 111.R13 - Revisão do Regulamento Sanitário Internacional, apoiando o processo de revisão e criando um grupo de trabalho intergovernamental aberto à participação de todos os Estados-membros, fixando o prazo até janeiro de 2004 para que este grupo apresentasse seus resultados à $113^{\text {a }}$ reunião do citado Comitê Executivo.

Logo após, em 28 de maio de 2003, a 56 assembléia Mundial da Saúde adotou a Resolução WHA 56.28, apoiando a recomendação do Comitê Executivo que fixava o prazo até janeiro de 2004 para a apresentação de um novo esboço do RSI, o qual deveria ser elaborado no decorrer daquele ano, com ampla discussão e apoio para realização das reuniões.

O curioso desta Resolução é que ela introduziu nos seus considerandos, como justificativa para a revisão do RSI, a existência de "novos riscos e ameaças para a saúde, derivados do possível uso deliberado de agentes com propósitos terroristas". Essa justificativa estaria em consonância com a Resolução WHA 55.16, de 18 de maio de 2002, sobre o uso intencional de agentes químicos, biológicos e materiais rádio-nucleares como ameaça à saúde pública, só que agora foi feita uma referência direta ao RSI, dentro desta perspectiva.

$\mathrm{Na} 113^{\text {a }}$ reunião do Comitê Executivo, em 15 de janeiro de 2004, foi apresentado o informe do Secretariado sobre os progressos dos trabalhos, no documento EB 113/3 Rev.1, dando conta, conforme planejado, da finalização de um novo esboço do RSI, que seria utilizado como documento de trabalho nas reuniões consultivas regionais as quais ocorreriam durante o primeiro semestre daquele ano. Planejava-se que entre julho e agosto fosse elaborado um novo rascunho, com base nestas reuniões regionais, para distribuição aos Estados-membros, com vistas à realização de uma reunião do grupo intergovernamental em novembro daquele ano. Todo esse esforço tinha como meta a finalização do novo texto com vistas a sua apresentação na Assembléia Mundial de Saúde, em maio de 2005.

O novo rascunho foi então apresentado aos Estados-membros e divulgado no site da OMS como o documento IGWG/IHR/Working paper/12.2003, 
de 12 de janeiro de 2003. Doravante este texto tende a ser referido como o "primeiro rascunho legal", tendo em vista ser um documento produzido no âmbito do grupo de trabalho intergovernamental, instituído pelo Comitê Executivo com esta finalidade.

Tratou-se de um texto que tentava consolidar o resultado de todas as discussões e consultas técnicas realizadas. Neste rascunho retirou-se qualquer menção à lista de doenças, e o instrumento de decisão discutido na reunião da Suécia, em 2002, foi apresentado no anexo 2, acrescido de exemplos que faziam referência ao uso intencional de agentes químicos, biológicos e materiais rádio-nucleares, como critérios para a inclusão dos eventos como de interesse para a saúde pública internacional; portanto, de notificação obrigatória.

Seguiu-se então uma rodada global de reuniões regionais para meIhorar o rascunho. Aconteceram reuniões na América do Sul (realizada no Rio de Janeiro), no Caribe de idioma inglês, no Caribe espanhol e América Central e na América do Norte. Por último, houve uma sessão conjunta com alguns representantes de cada sub-região, logo após a realização da reunião da América do Norte, em Ottawa, no Canadá.

Nessas reuniões, incentivou-se a presença de outras autoridades, além das sanitárias, tais como das áreas da agricultura, alfândega, comércio e relações exteriores, dentre outras, tendo em vista que, além da discussão técnica, existia um caráter político nesses fóruns. Com isso, muitos dos que delas participaram ainda não haviam entrado em contato com o tema e, com isso, estas reuniões também funcionaram como instrumento de sensibilização das diversas autoridades presentes, já que apesar da intensa chamada da OMS para a participação dos países durante todo o processo, em 2002 (sete anos após o início do processo), somente 57 países das seis regiões, dentre os 192 Estados-membros, tinham indicado pontos focais para o tema junto a OMS(27).

Para o grupo da América do Sul, os pontos chaves discutidos na reunião do Rio de Janeiro estavam relacionados a: a) interface com outros organismos intergovernamentais (como a World Organization for Animal Health, para epizootias) que deveriam ser citados no documento; b) imprecisão e inadequação de algumas definições, que deveriam ser melhoradas ou mesmo suprimidas, bem como harmonizadas com os termos de uso comum em outros tratados internacionais; c) a finalidade do RSI não deveria estar relacionada à "segurança", como proposto no texto, mas à "redução de riscos de propagação de doenças" ; d) aspectos relacionados à notificação e ao instrumento de decisão para a notificação (anexo 2) que se mostravam muito sensíveis, podendo levar ao excesso de notificação e pedidos de verificação.

(27) WHO - World Health Organization - Global crisis - global solutions: Managing public heath emergencies of international concern through the revised International Health Regulations. Genebra, 2002. 
O Brasil e o Peru foram escolhidos para representar a sub-região na reunião das Américas, realizada no Canadá, na qual, o ponto crítico foi a exclusão ou inclusão de lista de doenças para notificação. A posição dos países do MERCOSUL sempre foi a de manter uma lista auxiliar para monitoramento de doenças endêmicas, em processo de erradicação, ou mesmo erradicadas no mundo ou em determinadas regiões. Na reunião do Canadá, surgiu essa discussão; porém, sem haver consenso, sobre o uso ou não de listas e muito menos sobre quais doenças deveriam constar nestas listas, haja vista que também se cogitava incluir doenças pela sua vinculação com o bioterrorismo; mas, sem relevância epidemiológica, como o antraz.

Os resultados dessas reuniões foram então consolidados no documento A/IHR/IGWG/3, de 30 de setembro de 2004, como documento de trabalho para a primeira sessão do Grupo de Trabalho Intergovernamental, que ocorreu em Genebra, entre os dias 01 e 12 de novembro de 2004, conforme planejado. Nesta ocasião, o Brasil foi cogitado para inicialmente tomar parte na presidência da Sessão e, depois, para coordenar um dos subgrupos temáticos, relacionados aos temas de controle sanitário nos pontos de entrada. Em ambas as situações, a delegação declinou do honroso convite, por ser uma delegação já reduzida e com poucos especialistas em plenário. Porém, este fato demonstrou a liderança e prestígio que os países da América do Sul adquiriram, durante o processo de revisão, e que se fortaleceram ainda mais, no decorrer das negociações em Genebra, como teremos oportunidade de falar adiante.

Desta reunião podemos destacar os seguintes pontos relevantes para a saúde pública, que foram discutidos, a partir deste novo documento de trabalho:

1 - Objetivos do RS/ e sua relação com outros tratados. Deveriam ficar restritos aos aspectos de saúde pública, evitando-se utilizar o RSI como instrumento de verificação para outros propósitos, que não aqueles relacionados ao mandato da OMS, previstos na sua Constituição.

2 - Uso do termo "ameaça" (threat) x "risco" (risk). Discutida a impropriedade de usar-se o termo ameaça (potencial ou real, imediata), que estaria ligado a aspectos bélicos. A abrangência do termo risco para a saúde pública deveria ser analisada (ações preventivas das medidas permanentes, como exemplo).

3 - Direitos humanos $x$ saúde. Deveria ser levado em consideração que nem todos os princípios ou instrumentos de direitos humanos podem estar relacionados diretamente com a saúde pública, que, por sua natureza, se insere no campo do direito público-coletivo, ao contrário de alguns direitos da pessoa/indivíduo. Também é sinalizado sobre o risco da "hierarquização" dos tratados internacionais. Deveria se buscar a harmonização entre o RSI e outros instrumentos internacionais afins, não a submissão de um tratado ao outro. 
4 - Centro Nacional de Enlace nos Estados-membros e seu correspondente Ponto de Contato na OMS, ou nos escritórios regionais.

5 - Definição das Capacidades Básicas e prazos para sua implementação.

6 - Notificação, Instrumento de Decisão e lista de doenças de notificação obrigatória. Esse foi um ponto polêmico até o último momento, em todas as reuniões, pois a plenária estava dividida em posições opostas (nenhuma lista ou lista muito complexa que incluía doenças como o antraz por inalação). Já o instrumento de decisão necessitaria de sofrer um processo de validação, antes da entrada em vigor do $\mathrm{RSI}$ revisado.

7 - Uso de fontes não oficiais de informação. Era um tema sensível, muito relacionado à confiabilidade do sistema de verificação empregado e da transparência do processo.

Após essa primeira sessão do Grupo Intergovernamental, a qual compareceram delegados de 153 Estados-membros, quando as cartas já estavam na mesa, com os pontos críticos de difícil consenso já identificados, foi realizado em Brasília, nos dias 18 e 19 de novembro de 2004, outro Seminário do MERCOSUL para a revisão do RSI, onde foram analisados os resultados da primeira sessão do Grupo Intergovernamental para revisão do RSI, em Genebra. Nessa ocasião, sugeriu-se que se elevasse à decisão da Reunião de Ministros de Saúde do MERCOSUL a realização de uma oficina ampliada para todos os países integrantes da Comunidade Andina e do MERCOSUL, antes da próxima sessão do Grupo Intergovernamental que se realizaria em fevereiro de 2005, em Genebra.

Com a aprovação dos Ministros de Saúde do MERCOSUL, esse seminário aconteceu em Montevidéu, entre os dias 24 e 28 de janeiro de 2005, tendo como base um novo documento de trabalho, com a proposta da Presidência do Grupo Intergovernamental do texto da sessão anterior revisado (documento $A / I H R / / G W G / 2 / 2$ ), bem como outros três textos sobre fronteiras terrestres, mecanismos de reservas e sobre operações de alerta e resposta. Como resultado do Seminário, foi elaborado o "Documento de Montevidéu", com posições comuns dos dez países participantes do seminário, entregue em plenário, circulando cópias para todos os países durante a segunda sessão do Grupo Intergovernamental, realizada entre os dias 21 e 26 de fevereiro de 2004, em Genebra. Este documento foi um marco histórico no processo de negociação para a Revisão do RSI, por apresentar proposições de soluções razoáveis aos impasses surgidos em plenária e também por apresentar os países de língua espanhola e portuguesa da América do Sul como um só bloco.

Apesar de todos os esforços dos participantes para concluir o texto do novo regulamento, ainda nesta primeira reunião da segunda sessão do grupo, 
os trabalhos foram interrompidos às 4 horas da madrugada do sábado, dia 26 de fevereiro, sem que um consenso final houvesse sido atingido, já que a base de negociação era a de que tudo só estaria resolvido quando todos os pontos estivessem acordados.

Nova reunião, que daria continuidade à segunda sessão do Grupo Intergovernamental, foi marcada para a semana imediatamente anterior à 58로 Assembléia Mundial da Saúde, com início em 16 de maio de 2005.

Entre uma reunião e outra, considerando o sucesso alcançado com o seminário do MERCOSUL e Países Andinos e o "Documento de Montevidéu", foi realizado um novo seminário desta natureza, na cidade de Buenos Aires, entre os dias 25 e 27 de abril de 2005, quando $100 \%$ dos pontos pendentes para fechar o texto do RSI foram discutidos, havendo propostas consensuais em todos eles, que fizeram parte do "Documento de Buenos Aires", documento esse, elaborado para ser levado novamente à plenária e circulado entre os participantes do Grupo Intergovernamental. As discussões levadas a cabo nesse seminário e as propostas de texto alternativo tiveram como base o documento de trabalho para a segunda reunião da segunda sessão do Grupo Intergovernamental, documento A/IHR/IGWG/2/ Conf. paper 9, de 23 de março de 2005.

Novamente o documento da América Latina fez diferença em plenária, agilizando o processo de negociação, já que expressava a posição de dez países de forma transparente e construtiva, tendo sido este documento usado várias vezes como referência para as discussões naquele fórum e acatado em quase toda a sua totalidade, assim como ocorreu com o Documento de Montevidéu.

Nessa última fase de negociação os temas pendentes críticos se referiam às exigências de documentos sanitários, o direito de um país estipular medidas adicionais para o controle sanitário, a retirada de referências às forças armadas, mecanismos de aprovação de reservas, a remoção de cláusula sobre federalismo e responsabilidade das instâncias subnacionais, anexo 2 e seu instrumento de decisão (algoritmo) e uso de lista de doenças. 0 consenso final foi obtido às 4 horas e 30 minutos da madrugada do dia 14 de maio de 2005, tendo sido adotado na plenária da 58ª Assembléia Mundial de Saúde na quarta-feira do dia 18 de maio de 2005.

\section{O REGULAMENTO SANITÁRIO INTERNACIONAL (2005) APROVADO NA. $58^{\circ}$ AMS}

O objetivo e a finalidade do RSI (2005) são explicitados no seu art. $2^{\circ}$ como:

"... prevenir, proteger, controlar e prover resposta em saúde pública contra a disseminação internacional de doenças, estritamente relacionado 
aos riscos para a saúde pública, e com isso evitar-se interferência desnecessária ao tráfego e comércio internacional."

O RSI (2005) mantém, assim, a preocupação do regulamento sanitário em vigor, com respeito a sua função de evitar a disseminação de doenças, sem, no entanto, interferir desnecessariamente no tráfego internacional. Há implícita a idéia de que os eventos sérios e inesperados, além daqueles advindos de riscos conhecidos, são inevitáveis e que, em um mundo globalizado, um evento em um país pode vir a ser um problema para vários países também. para:

Trata-se de um Regulamento que amplia o uso de lista de doenças

Lista de doenças para notificação imediata pelos países, como é o caso da VARÍOLA, POLIOMIELITE por poliovírus selvagem, GRIPE HUMANA causada por um novo subtipo de vírus e da SARS;

Lista de doenças cujos novos casos devem ser analisados à luz de instrumento de decisão para avaliação e notificação de eventos que possam constituir-se uma emergência de saúde pública de importância internacional (constante do anexo 2). São estas: CÓLERA, PESTE PNEUMÔNICA, FEBRE AMARELA, FEBRES HEMORRÁGICAS VIRAIS (EBOLA, LASSA, MARBURG), FEBRE DO NILO OCIDENTAL e outras doenças de especial importância nacional ou internacional, tais como dengue, febre do vale de Rift e doença meningocócica.

Caso analisemos atentamente as doenças listadas, verificaremos que grande parte delas são doenças transmitidas por vetores e que, em caso de situações epidêmicas de risco para a disseminação internacional, as ações de controle sanitário nos pontos de entrada assumem fundamental importância, bem como se ressalta a necessidade de uma efetiva vigilância ambiental, de informação em saúde e de ações intersetoriais integradas para que este controle tenha sucesso.

Além da utilização de listas de doenças, o novo Regulamento prevê que se possam verificar todos os eventos que signifiquem um risco para a saúde pública internacional, independentemente da sua origem (natural, acidental ou intencional) ou fonte (biológica, química ou mesmo rádio-nuclear) com vistas à adoção de medidas sanitárias temporárias ou permanentes. Para tanto, além das notificações oficiais dos países, outras fontes de informação serão utilizadas para solicitar esta verificação, tais como as notícias na imprensa, artigos científicos e mesmo a internet.

O Regulamento revisado amplia a responsabilidade da Organização Mundial da Saúde para a verificação de eventos que possam vir a ser uma emergência de saúde pública de importância internacional, bem como para apoiar os países no desenvolvimento de capacidades básicas de alerta e resposta a estes eventos. 
Por sua vez, o Regulamento revisado traz novas obrigações aos Estadosmembros, no tocante à implementação de capacidades nacionais previstas neste instrumento. Destacam-se aquelas previstas no seu anexo 1 que compreende atividades de vigilância, informação, notificação, verificação, resposta e colaboração em todos os níveis, desde a comunidade local até o nivel federal, inclusive nos portos, aeroportos e passagens de fronteiras terrestres. Não mais estamos lidando apenas na ênfase do controle dos pontos de entrada; mas, sim na rápida detecção e controle de eventos que representem risco para a saúde pública, ainda em solo nacional, a fim de impedir a sua disseminação por todo o território brasileiro, ou além-fronteira.

As medidas sanitárias rotineiras nos pontos de entrada continuam sendo vistas como necessárias e devem ser modernizadas à luz do RSI (2005). Para tanto este Regulamento discrimina, na Parte IV - PONTOS DE ENTRADA e no seu anexo 1, dentre outros, as responsabilidades dos paísesmembros para manter capacidades com vista à adoção de medidas sanitárias permanentes e emergenciais nestas áreas.

A maior mudança, quanto à saúde a bordo das embarcações, está na introdução do Certificado de Controle Sanitário a Bordo (ou da sua isenção ou prorrogação) que deve ser renovado a cada seis meses, mediante inspeção pelas autoridades sanitárias dos portos designados pelos países, com esta finalidade. Na prática ele substituirá o atual Certificado de Desratização ou de Isenção de Desratização, que deixa de existir, e envolverá uma inspeção sanitária mais complexa, que tem como objetivo verificar a gestão dos riscos sanitários realizada a bordo.

Quanto às instalações nos pontos de entrada, o princípio geral é o de que o país designe portos e aeroportos específicos para o tráfego internacional, onde se obriga a manter as capacidades requeridas pelo Regulamento, dentre elas:

1 - Capacidades em caráter permanente:

Pessoal treinado para inspeção de embarcações com vistas à emissão do Certificado de Controle Sanitário a Bordo, sua Extensão ou Isenção;

Programas de Inspeção continuada com vistas à garantia de um ambiente seguro aos viajantes que usam as instalações do ponto de entrada, com relação a: suprimento de água potável; estabelecimentos alimentícios; sanitários públicos; serviços apropriados para destinação de resíduos sólidos e líquidos; outras áreas de risco potencial;

Programa específico e pessoal treinado para o controle de vetores e reservatórios, dentro do porto ou aeroporto e numa área adjacente de 400 metros;

Acesso à coleta de amostras para exames laboratoriais; serviço médico para avaliação; diagnóstico e atenção à saúde dos viajantes, com equipe, 
equipamentos e instalações adequadas; equipamentos e equipe para transporte de viajantes enfermos e serviço médico apropriado.

2 - Capacidades para Responder a Eventos que Possam se Constituir numa Emergência de Saúde Pública de Interesse Internacional:

Instituir e manter Plano de Contingência para Emergência em Saúde Pública - nomear coordenadores e pessoas para contato nos pontos de entrada relevantes e nas instituições de saúde pública e em outras agências e serviços;

Prover avaliação e cuidados de saúde para viajantes e animais. Arranjos com serviços médicos e veterinários para isolamento, tratamento e outros serviços de apoio necessários;

Prover espaço apropriado para entrevistar pessoas suspeitas ou afetadas em separado de outros viajantes;

Prover avaliação e, caso seja requerida, quarentena para viajantes suspeitos, preferencialmente fora das instalações do ponto de entrada;

Aplicar medidas recomendadas em bagagens, carga, contêineres, meios de transporte, bens ou malas postais, em instalações especialmente projetadas e equipadas para desinsetização, desratização, desinfecção, descontaminação ou outro tratamento adequado;

Aplicar medidas de controle na entrada e saída de viajantes;

Fornecer acesso a equipamentos especialmente projetados, e pessoal treinado com equipamento, proteção individual apropriada, para a transferência de viajantes que possam ser portadores de infecção ou contaminação.

No Anexo 4 há recomendação no sentido de que, durante a aplicação das medidas sanitárias, evite-se ao máximo ferir ou causar desconforto a pessoas ou danificar bagagens, carga, contêineres, meios de transporte e bens. As medidas de controle devem ser aplicadas, preferencialmente, quando o meio de transporte e seus compartimentos de carga estiverem vazios. Todas as medidas sanitárias adotadas devem ser atestadas por escrito e o documento entregue ao responsável por meio de transporte.

Por outro lado, esse mesmo anexo estabelece que o operador do meio de transporte deva facilitar:

Inspeções da carga, contêineres e meio de transporte;

Exames médicos das pessoas a bordo;

Aplicação das medidas sanitárias previstas no Regulamento;

Prover informações de saúde pública relevantes, requeridas pelo Estadoparte; 
Apresentar certificados válidos às autoridades sanitárias; e

Declarações de Saúde a bordo das embarcações e aeronaves.

Existe provimento que traz medidas específicas com vistas ao controle de doenças transmitidas por vetores, no anexo 5, para que, além das atividades do Plano de Controle de Vetores (em caráter permanente), exercido num raio de, no mínimo, 400 metros das instalações do ponto de entrada, deva haver capacidade para aplicação de medidas específicas para o controle de vetores nos meios de transporte oriundos de áreas para as quais a OMS recomenda estas medidas, em caráter temporário ou permanente. Caso o resultado das medidas aplicadas necessite ser acompanhado no seguimento da viagem, compete à autoridade sanitária avisar ao próximo porto ou aeroporto de destino, além dos devidos registros escritos a bordo.

Atenção especial também deve ser dada à aplicação de medidas de controle de vetores aos meios de transporte que venham de áreas afetadas por doença transmitida por vetor presente no território do ponto de entrada.

Além destas medidas, as quais podem ser planejadas e introduzidas na rotina diária das autoridades sanitárias, um meio de transporte pode ser considerado suspeito e suscitar medidas excepcionais imediatas, quando:

Tenha um possível caso de doença transmitida por vetor a bordo;

Um possível caso de doença transmitida por vetor tenha ocorrido a bordo durante uma viagem internacional;

Se vier de uma área afetada, cujo período de viagem transcorrido possa ainda significar a possibilidade de vetores a bordo serem transmissores de doença.

Essas medidas trazem a responsabilidade da OMS de informar aos países sobre áreas afetadas com risco de doenças transmitidas por vetores, bem como dos países adotarem medidas de controle nos pontos de entrada, as quais têm como propósito:

Evitar a entrada de novos vetores a uma área indene;

Evitar a transmissão vetorial em áreas infestadas por vetores comuns;

Evitar a disseminação de doenças transmitidas por vetores no meio de transporte, no país e internacionalmente;

Evitar a adoção de medidas excessivas de controle de vetores nos meios de transporte, mediante a designação de áreas de risco e aplicação de métodos e materiais recomendados pela OMS.

A FEBRE AMARELA e a MALÁRIA são doenças onde existem áreas de transmissão de caráter endêmico na América do Sul, na América Central e na África, além da Ásia, e que requerem atenção constante das autoridades sanitárias, para a aplicação de medidas de controle de vetores nos meios de transporte e quanto à saúde dos viajantes. 
Recentemente outra doença transmitida por mosquitos trouxe preocupação para as autoridades sanitárias de portos e aeroportos. Trata-se da FEBRE DO NILO ORIENTAL, disseminada por boa parte da América do Norte, nos Estados Unidos, cuja expansão vem sendo verificada rumo ao continente sul-americano, quer seja pela rota migratória de aves selvagens, quer seja pelo fluxo do tráfego internacional.

As doenças transmitidas por vetores insetos, que têm na desinsetização dos meios de transportes a principal estratégia de controle nos portos e aeroportos, têm feito ressurgir debates sobre a eficácia desta medida e seu impacto para a saúde dos viajantes e para o ambiente. Essas discussões estão sendo levadas tanto para fóruns internacionais intergovernamentais, como para a Organização da Aviação Civil Internacional (OACl) e para a própria OMS. Na prática, tenta-se substituir o uso de produtos químicos na presença de passageiros a bordo, por procedimentos residuais antes da viagem ou mesmo a busca de procedimentos mecânicos que possam impedir a entrada de insetos a bordo dos meios de transporte, tais como "cortinas de vento" nos fingers de embarque nos aeroportos. Ainda não se chegou a uma medida que possa, de fato, substituir o uso de inseticidas a bordo, para meios de transporte que partem de portos e aeroportos infestados de insetos transmissores de doenças.

Dos comentários sobre medidas específicas para controle de doenças transmitidas por vetores, temos a dizer que a melhor forma de lidar com este problema é seguir as recomendações previstas no RSI, no sentido de manter programas específicos com pessoal treinado para o controle de vetores e reservatórios nos pontos de entrada, de modo a manter estas áreas livres de infestação de mosquitos e outros transmissores de doenças.

Associada às medidas de controle dos vetores e reservatórios, o Regulamento mantém como única exigência de vacinação e profilaxia, a imunização contra a FEBRE AMARELA, nos seus anexos 6 e 7. Essa exigência pode ser feita aos viajantes que venham de área designada pela OMS para o risco de transmissão de febre amarela e que haja vetor presente no território do país de destino ou escala. Caso o viajante não consiga provar a sua imunização, mediante a apresentação de um certificado de vacinação válido, este estará sujeito à quarentena de até seis dias (período de incubação para a febre amarela), desde a última possivel exposição à infecção.

Estas medidas para prevenção e controle da FEBRE AMARELA assumem especial importância para a América do Sul e a África, que são as áreas onde existem países com risco para a transmissão da doença. Nessas regiões, devido às características do seu ecossistema, não podemos impedir a circulação viral da FEBRE AMARELA SILVESTRE (cujos hospedeiros naturais são os primatas não-humanos e o principal vetor e reservatório, o mosquito do gênero haemagogus janthinomys). Mas, temos a obrigação de impedir a introdução da FEBRE AMARELA URBANA, que não ocorre nas Américas 
desde 1954, principalmente em áreas onde temos a presença do vetor e reservatório Aedes aegypti, que também é o mosquito transmissor da DENGUE, e do qual o homem é o principal hospedeiro de importância epidemiológica. Esta é uma doença de alta letalidade, que pode variar de.23\% a $100 \%$ (Ministério da Saúde, 2004), em função das medidas adotadas, para a qual a detecção precoce e o diagnóstico rápido são fundamentais, não apenas para a sobrevida do paciente, mas também para impedir a sua propagação, já que a vacinação existe e é eficiente para bloquear a transmissão na população afetada. Nesse sentido, as atividades de controle sanitário nas áreas de portos, aeroportos e fronteiras desempenham um papel fundamental para o controle da disseminação dessa doença nos pontos de entrada, geralmente próximos aos centros urbanos.

O RSI (2005) estabelece, em seu artigo 24, que os Estados-membros adotarão todas as medidas praticáveis, no sentido de que os operadores dos meios de transporte, incluindo-se aí as embarcações, aeronaves e veículos terrestres, adotem e cumpram as medidas sanitárias previstas no Regulamento, especialmente aquelas previstas no anexo 4 (prescrições técnicas específicas para os meios de transporte) e no anexo 5 (medidas para controle de doenças transmitidas por vetores).

\section{CONCLUSÃO}

No decorrer deste trabalho pudemos verificar a estreita relação existente entre as medidas sanitárias adotadas e a compreensão da história natural das doenças, em cada época da história da civilização. Por outro lado, o comércio internacional sempre desempenhou um papel importante na disseminação de doenças no mundo. Sendo assim, as medidas de controle sanitário adotadas têm sempre a possibilidade de ter um impacto no tráfego e comércio internacional.

Com a evolução das relações entre as nações surgem também os acordos sanitários entre países, que tentam, ao mesmo tempo, impedir a propagação de doenças e evitar barreiras injustificadas ao tráfego e comércio internacional. No século $X X$, os organismos internacionais multilaterais, assumiriam um papel fundamental na regulação de práticas internacionais, neste início do século XXI, inclusive no campo da saúde pública.

Hoje não apenas as doenças transmissíveis justificam a existência do Regulamento Sanitário Internacional, como vimos, mas também qualquer evento que possa ameaçar a saúde pública internacional, independentemente da sua origem (natural, acidental ou intencional) ou fonte (biológica, química ou rádio-nuclear). Amplia-se assim o escopo das ações de vigilância em saúde, preconizadas pelo RSI (2005), sem, no entanto, se perder de vista o seu bem maior, que é a saúde pública como finalidade última. 
Para prevenir, controlar e responder aos eventos que possam significar uma emergência de saúde pública internacional, surge o RSI (2005), que atualiza as medidas sanitárias do regulamento em vigor e que são necessárias ao mundo globalizado atual. Porém, sua implementação, assim como ocorreu durante o processo de revisão, necessitará de uma ampla articulação interna e externa, entre os diversos setores da sociedade, envolvidos no tráfego e comércio internacional, e entre os diversos segmentos responsáveis pela saúde pública de cada país, bem como de uma ampla cooperação internacional e apoio irrestrito dos organismos internacionais, em especial da Organização Pan-Americana de Saúde e da Organização Mundial de Saúde. Neste sentido, a correta compreensão da sua dimensão e a interpretação do seu texto são fundamentais para o processo de sua ratificação pelo Brasil, bem como para que o Regulamento possa ser adequadamente inserido no arcabouço jurídico nacional.

\section{REFERENCIAS}

FARREL, Jeannette. A assustadora história das pestes \& epidemias. São Paulo: Ediouro, 2003.

NAVARRO Y GARCIA, Ramon; Historia de la sanidad marítima en España, Instituto de Salud Carlos III - Ministerio de Sanidad y Consumo, Madrid, (1995-96).

OMS - Organização Mundial da Saúde - Regulamento Sanitário Internacional, Genebra, 1983.

OMS - Organización Mundial de la Salud - Reglamento Sanitario Internacional (2005), in World Health Assembly - WHA58.3, Genebra, 2005 (español).

OPAS - Organização Pan-Americana de Saúde. Regulamento Sanitário Internacional: Perspectivas da Região das Américas. Conselho Diretor, CD45/ 12, 2004 Disponivel em: site <www.paho.org>.

Ministério da Saúde. Secretaria de Vigilância em Saúde. Departamento de Vigilância Epidemiológica - Doenças Infecciosas e Parasitárias: Guia de Bolso/3. ed. - Brasília: Ministério da Saúde, 2004.

SILVA, Julieta S.V. da et SOUZA, Cristina C. L. de; Água de lastro e bioinvasão; Rio de Janeiro: Interciência, 2004.

SOARES, Guido F.S. O direito internacional sanitário e seus temas: Apresentação de sua incômoda vizinhança, in; Revista de Direito Sanitário, São Paulo, v. 1, n.1, p. 49-88, 2000.

WALDMAN, Eliseu A. O controle das doenças infecciosas emergentes e a segurança sanitária, Revista de Direito Sanitário, São Paulo, v. 1, n. 1, p. 88106, 2000. 
WHO - World Health Organization - Weekly Epidemiological Record de n. 31 , ano $71^{\circ}, 2$ outubro de 1996, p. 233-234.

WHO - World Health Organization; Sanitation on Ships - Compendium of outrbreaks of foodboorne and waterborne disease and Legionnaires' disease associated with chips 1970-2000. Genebra, Suiça, 2001.

WHO - World Health Organization - Global crisis - global solutions: Managing public heath emergencies of international concern through the revised International Health Regulations. Genebra, 2002. 